\title{
ESTUDO DA VARIAÇÃO GRAFEMÁTICA PRESENTE EM SONETOS FEMININOS DE AMOR PUBLICADOS NO JORNAL DAS MOÇAS DA DÉCADA DE 1920-1930
}

\section{$\underline{\text { Eliane Cristina Ormonde Leitão Mosquezi }}{ }^{1}$; Josenilce Rodrigues de Oliveira Barreto²}

\author{
1.Bolsista PIBIC/CNPq, Graduanda em Letras Vernáculas, Universidade Estadual de Feira de Santana, e-mail \\ j.e.mosquezi@hotmail.com. \\ 2. Orientadora, Departamento de Letras e Artes, Universidade Estadual de Feira de Santana, e-mail \\ nilce11.barreto@gmail.com
}

Palavras - chave: Jornal das Moças; Sonetos Femininos; Variação grafemática.

\section{INTRODUÇÃO}

Entender os processos de transformação da língua escrita, por meio da história da língua, segundo Faraco (2005), é estudar a origem e o desenvolvimento das mudanças pelas quais passam as línguas. Por isso, é necessário que nós, falantes, percebamos a relevância de investigar essas mudanças linguísticas, ao longo do tempo, através da sincronia e diacronia, ambas com a finalidade de estudar essas modificações linguísticas.

Entretanto, houve grandes períodos da Linguística Histórica, que contribuíram para essas reflexões sobre as transmutações das línguas, como a própria Filologia que estuda manuscritos de épocas pretéritas há milênios. Assim, o propósito de pesquisar e analisar os sonetos femininos de amor da década de 1920 a 1930, constantes no Jornal das Moças, os quais eram enviados a seção de correspondência do referido. Além disso, estão as grandes contribuições do Jornal das Moças na formação leitora dessas mulheres nesse período, o que é de extrema importância para apontar a representação desse periódico semanal, o qual era destinado ao público feminino da sociedade carioca, e de outras capitais brasileiras no século $\mathrm{XX}$, cujas suas publicações eram: Poesias e sonetos, noções de moda, propaganda de remédios, e outros temas, condizendo com os padrões da época.

Portanto, objetivando examinar as variações grafemáticas expostas nos sonetos permite analisar as produções textuais dessas leitoras. De autoria de Aristotelina Leite CAMARGOS, o soneto Tarde demais (1923), e de Lorena - Mlle. INCAUTINHA, cujo soneto Amar e ser amada (1924), os quais evidenciam as mudanças grafemáticas do período de 1920-1930, escrita obsoleta se comparado a vigente.

\section{METODOLOGIA}

Para a realização desta pesquisa, foram utilizados os sonetos femininos de amor, recolhidos nos periódicos do Jornal das Moças de 1920-1930, sendo este, o corpus de estudo desse trabalho. Enquanto as leituras feitas, foram embasadas em alguns teóricos da linguística, pois assim, para obter êxito nas análises da escrita, através do estudo das variações grafemáticas, e da própria análise dos aspectos dessas variações linguísticas. Esses procedimentos foram utilizados para evidenciar a mudança da escrita obsoleta, se comparando a vigente. Apontando os fenômenos linguísticos que causaram essas mudanças na língua escrita. Para metodologia deste trabalho, embasei nos seguintes aspectos: 
- Coleta de sonetos de amor escritos por mulheres e publicados no Jornal das Moças, na década de 1920 - 1930;

- Leitura e análise linguística dos sonetos;

- Levantamento das variações grafemáticas no texto;

Portanto, trabalhar com essas análises linguísticas, através do embasamento de alguns teóricos como: Bagno (2007), Brito (2005), Farias (2010), Faraco (2005), Silva (2011), e que foram utilizados para o desenvolvimento desse trabalho, abordam as mudanças linguísticas de forma expansiva ao longo do tempo.

\section{RESULTADOS E DISCUSSÃO}

Ao longo da pesquisa foram analisados os sonetos de amor da década de 1920-1930, sendo os que estão em evidencia nesse contexto, e que serão analisados.

Periódico ${ }^{\circ} 00394$ (04 de janeiro de 1923) / Periódico nº 00453 (21 de fevereiro de 1924)
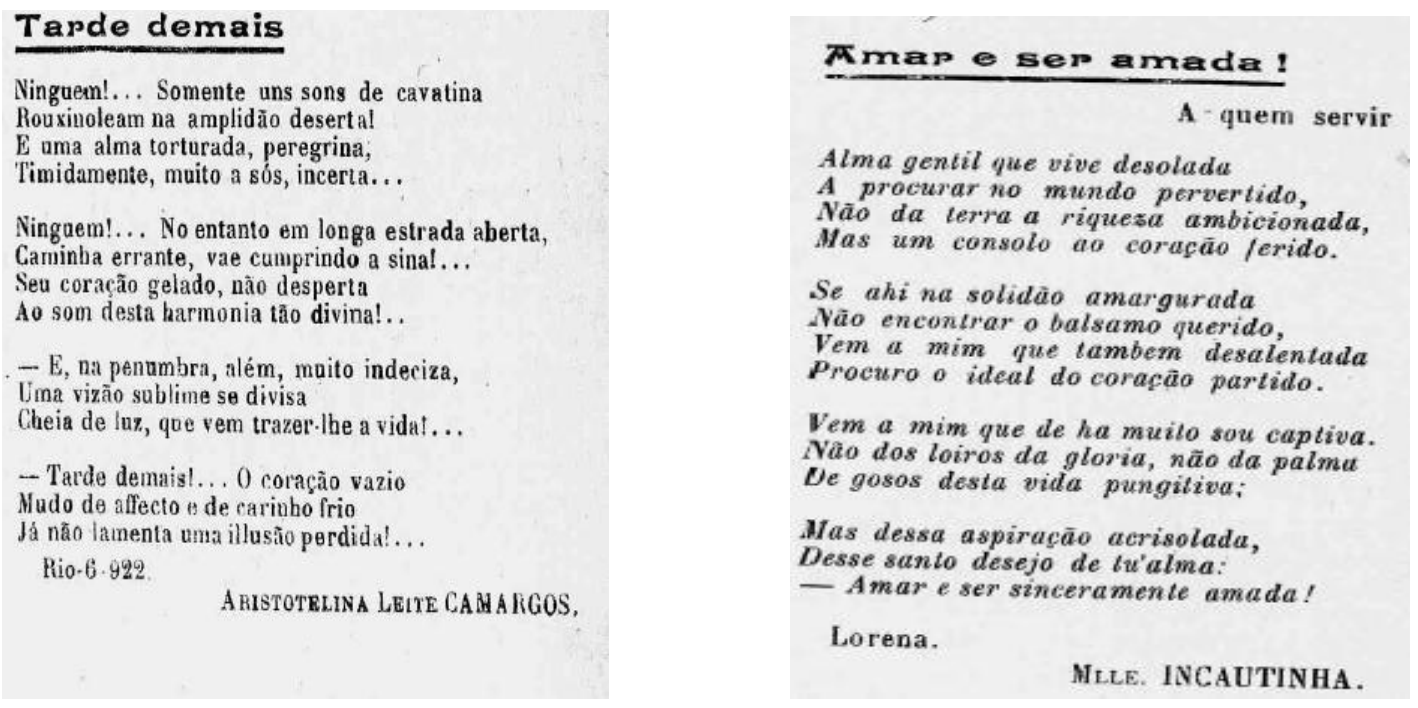

Estes sonetos aparecem do lado direito no referido periódico. A escrita dos sonetos femininos de amor daquela década, ou seja, o acordo ortográfico da época de 1920 evidencia algumas palavras que sofreram transformações, tornando-as obsoletas, conforme as mudanças do acordo ortográfico.

Um dos responsáveis pelos processos que ocasionaram essas mudanças ortográficas é o fenômeno conhecido como variação grafemática, que tem como definição "mudança na escrita de uma palavra". Em paralelo a isso, a Linguística Histórica estuda todos os contextos de transformações que ocorreram nas línguas, logo de acordo com Faraco (2003, p. 91): A Linguística Histórica investiga e estuda os diferentes processos de mudanças ocorrentes na história de uma língua ou de uma família de línguas, com base em pressupostos mais gerais a respeito da mudança linguística como um todo.

Por isso, a importância de abordar as fases do acordo ortográfico na análise dos sonetos tem a finalidade de apresentar a relação da grafia com o contexto da época, e as mudanças linguísticas. De acordo com Farias (2010, p. 97), o acordo ortográfico da Língua Portuguesa passou por três períodos, os quais foram: 
(1) o fonético, que se inicia com os primeiros documentos redigidos em português e se estende até o século XVI;

(2) o pseudoetimológico, que se inicia no século XVI e vai até o ano de 1911,

(3) quando se inicia o terceiro e último período denominado de moderno ou reformado.

Entretanto, analisar as semelhanças gráfica e sonora, por meio dos sonetos, requer uma atenção para que sejam verificadas as mudanças ocorridas na escrita. Por isso, estudar os processos fonéticos das línguas, conforme Bagno (2007) é função da fonética histórica, que analisa a evolução desses elementos, ao longo do tempo, como, por exemplo, os fones e os sons da fala. Todos esses fatores, segundo o autor (2007), internos ou externos, não são propriamente causas, mas condições de mudança linguística. Deste modo, os processos fonéticos se relacionam com três grupos: vogais, semivogais e consoantes.

A partir dessas abordagens, serão feitas as análises que inferem as fases do acordo ortográfico nos sonetos, Tarde demais, de 1923, em que a primeira estrofe do soneto se insere na $3^{\text {a }}$ fase do período ortográfico, mediante a falta de acento apresentado na palavra "Ninguem". Segundo Silva (2011), o acordo ortográfico moderno é representado por uma de suas características principais, que é a profundidade dos acentos.

Enquanto a segunda estrofe, na qual há a palavra vae no verso: "Caminha errante, vae cumprindo a sinal...", leva-nos a afirmar que se trata da $1^{\text {a }}$ fase do período fonético, por encontrarmos um ditongo nesta palavra. Já na terceira estrofe, identificamos a presença da palavra indeciza, no verso: "- E, na penumbra, além, muito indeciza", a qual também se insere na $1^{\mathrm{a}}$ fase do período fonético com alternância entre os grafemas $\langle\mathrm{z}\rangle \mathrm{e}\langle\mathrm{s}\rangle$, porque ambos podem representar o mesmo fonema em posição intervocálica /z/, uma vez que as vogais sonorizam a consoante surda. Assim, a variação nesses usos se dava por conta da confusão estabelecida em relação às regras ortográficas.

Como podemos identificar, na quarta e última estrofes apontamos a presença da $2^{\mathrm{a}}$ fase do período ortográfico, conhecida como pseudoetimológico, na qual há a consoante geminada /ff/, exposta no segundo verso: "Mudo de affecto e de carinho frio", que ocorre por conta da presença de consoantes geminadas, por conta da influência pseudoetimologizante, fenômeno conhecido como variação etimologizante.

\section{ANÁLISE DO CORPUS}

\begin{tabular}{|c|c|c|c|}
\hline PALAVRAS & OCORRÊNCIAS & ANÁLISES & CONTEXTO \\
\hline $\begin{array}{l}\text { Ha } \\
\text { (Soneto: } \\
\text { Amar e ser } \\
\text { amada). }\end{array}$ & $3^{\mathrm{a}}$ estrofe - linha 1 & $\begin{array}{l}\text { Período denominado moderno, } \\
\text { simplificado ou reformado, que } \\
\text { coincide com o acréscimo do acento } \\
\text { <á> nas palavras. }\end{array}$ & $\begin{array}{l}\text { "Vem a mim que } \\
\text { de ha muito sou } \\
\text { captiva". }\end{array}$ \\
\hline $\begin{array}{l}\text { Affecto } \\
\text { (Soneto: } \\
\text { Tarde } \\
\text { demais). }\end{array}$ & $4^{\mathrm{a}}$ estrofe- linha 2 & $\begin{array}{l}\text { Presença de consoantes geminadas, } \\
\text { por conta da influência pseudo } \\
\text { etimologizante, fenômeno conhecido } \\
\text { como variação etimologizante. }\end{array}$ & $\begin{array}{ll}\text { "Mudo } & \text { do } \\
\text { affecto e } & \text { de } \\
\text { carinho frio". } & \end{array}$ \\
\hline
\end{tabular}


A análise do segundo soneto, Amar e ser amada (1924), do periódico 00453, apresenta características do período do acordo ortográfico. Na segunda estrofe há a grafia ahi, sofreu aspiração do h, "Se ahi na solidão amargurada". Enquanto na grafia ha e gloria, destacam as frases, "Vem a mim que de ha muito sou captiva"/ "Não dos loiros da gloria, não da palma", apontam $3^{\text {a }}$ fase do período moderno, segundo a referida a autora Silva citada acima, período marcado pela introdução profunda do acento. Já a grafia tu'alma é uma aglutinação de palavras.

\section{CONDIDERAÇÕES FINAIS}

Abordar as mudanças ortográficas evidencia a relevância de se estudar as fases pelas quais passou o acordo ortográfico da Língua Portuguesa. Assim, ao analisarmos alguns sonetos, escritos por mulheres no período de 1920-1930 e publicados no Jornal das Moças, identificamos que o referido jornal incentivou às mulheres, através da oportunização de publicação de seus sonetos, que eram enviados pelas próprias leitoras à seção de correspondências do jornal, a produzir textos relevantes para a Literatura daquele período. Assim, os sonetos publicados, no referido jornal, permitiram que estudássemos as modificações sofridas pela ortografia da Língua Portuguesa naquele período, o que é importante para detectarmos quais as grafias que tornaram ou não obsoletas na atualidade.

\section{REFERÊNCIAS}

BAGNO, Marcos. Gramática Histórica. Brasília: Universidade de Brasília, 2007.

\section{BIBLIOTECA NACIONAL DIGITAL DO BRASIL.}

Disponível em: <http://hemerotecadigital.bn.br/acervo-digital/jornal-mocas/111031>. Acesso em: 08 agosto 2016.

BRITO Cristina. Atribuições do filólogo. SOLETRAS. São Gonçalo: UERJ, Ano V, no 09. p. 67-71, jan/jun.2005. Disponível em:〈www.e-publicacoes.uerj.br/index.php/soletras/article> Acesso em: 05 julho 2017.

FARIAS, Emilia Maria Peixoto. A Escrita nos autos de querela do século XIX: do passado ao presente. Cadernos do CNLF, vol. XIV, n. 2, t. 1, p. 97-108, 2010. Disponível em: <http://www.filologia.org.br/xiv_cnlf/tomo_1/097-108.pdf>. Acesso em: 19 julho 2017.

FARACO, Carlos Alberto. Linguística histórica: uma introdução ao estudo da história das línguas. São Paulo: Parábola Editorial, 2005.

HIGOUNET, Charles. História concisa da escrita. São Paulo: Parábola Editorial, 2003.

SILVA, Daianna Quelle da Silva Santos da. "Annos ou Anos": Estudo das variações grafemáticas em documentos manuscritos do acervo de Monsenhor Galvão. Rio de Janeiro: CiFEFiL, 2011. Cadernos do CNLF, Vol. XV, $\mathrm{N}^{\circ}$ 5, t. 1.. Disponível em : $<$ http://www.filologia.org.br/xv_cnlf/tomo_1/26.pdf>. Acesso em: 15 abril 2017. 